\title{
The Carit Maneuver: A Novel Approach for the Relief of Shoulder Dystocia-A Case Series
}

\author{
Alfredo F Gei, MD ${ }^{1}$ Jorge Suarez Mastache, $\mathrm{MD}^{2}$ \\ ${ }^{1}$ Division of Maternal Fetal Medicine, Department of Obstetrics and \\ Gynecology, The Methodist Hospital, Houston, Texas \\ 2 The Department of Obstetrics and Gynecology, Hospital Rafael \\ Calderón Guardia, San José, Costa Rica \\ ${ }^{3}$ Division of Maternal Fetal Medicine, Department of Obstetrics and \\ Gynecology, The University of Texas Medical Branch, Galveston, \\ Texas \\ ${ }^{4}$ Escuela de Medicina y Ciencias de la Salud, Tecnológico de \\ Monterrey, Monterrey, Nuevo León
}

Am J Perinatol Rep 2020;10:e133-e138.
Luis D. Pacheco, $\mathrm{MD}^{3} \quad$ Mariana Villanueva, $\mathrm{MD}^{4}$

Address for correspondence Alfredo F. Gei, MD, Department of Obstetrics and Gynecology, The Methodist Hospital, 6400 Fannin, Suite 1900, Houston, TX 77030 (e-mail: alfredo.gei@gmail.com).

\begin{abstract}
Keywords

- shoulder dystocia

- shoulder girdle dystocia

- rotational maneuver

- Carit maneuver
\end{abstract}

The failure of the shoulder girdle to deliver spontaneously or with minimal assistance, known as shoulder dystocia, continues to represent the "infrequent, unanticipated and unpredictable nightmare of the obstetrician." 1

Shoulder dystocia complicates 0.2 to $3.0 \%$ of all vaginal deliveries and it is associated with significant neonatal morbidity with potential for significant delays in the transition to extrauterine life (low Apgar scores; hypoxia; acidosis), fetal trauma (clavicular and upper extremity fractures; brachial plexus injuries), and occasional fetal or neonatal mortality. ${ }^{2-5}$

The management of shoulder dystocia cases has been recognized as largely empirical and current guidelines of management are largely based on expert opinions. ${ }^{2-4,6-9}$

Although several maneuvers have been and continue to be described, no randomized clinical trials or laboratory experiments have compared these techniques directly. ${ }^{2-4,7-9}$ received

April 27, 2019

accepted after revision

June 28, 2019
DOI https://doi.org/

10.1055/s-0040-1708498. ISSN 2157-6998.
Copyright $\odot 2020$ by Thieme Medical Publishers, Inc., 333 Seventh Avenue, New York, NY 10001, USA. Tel: +1(212) 760-0888.
License terms

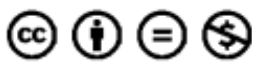


Unfortunately, single interventions have a limited success. In the study by McFarland et al, relief of shoulder dystocia required at least two maneuvers in $39.5 \%$ of the cases; $11.6 \%$ required three maneuvers and $4.7 \%$ required four. ${ }^{10}$ One of the most popular and least invasive interventions, the McRobert's maneuver, has a reported success rate in the range of $42 \%$ to $58 \%$; the latter when combined with suprapubic pressure. ${ }^{2,10-12}$ The use of additional maneuvers beyond the McRobert's maneuver has been associated with higher fetal weights, longer labors, and higher rates of fetal injury. ${ }^{2-4,10,11}$ Considering these associations, shoulder girdle dystocia not responding to initial maneuvers can be considered a more severe subset of this clinical problem.

In the early 1990s, an obstetric maneuver for the relief of shoulder dystocia was developed by one of the authors (JSM) at the Instituto Materno-Infantil Alfonso Carit in San José, Costa Rica. To date this intervention has never been formally researched or reported.

The purpose of this communication is to describe the Carit maneuver and characterize its mechanism of action through the prospective experience in eight clinical observations.

A literature review was performed to summarize the maneuvers aimed at the management of the relief of shoulder dystocia and set the context for the Carit maneuver.

\section{Methods}

Between 2003 and 2006, two of the authors successfully assisted eight cases of shoulder dystocia at the John Sealy Hospital of the University of Texas Medical Branch in Galveston, Texas (UTMB) using the Carit maneuver. This level III General Hospital serves as a referral perinatal center for the Southeast part of the State. It has an active Obstetrics and Gynecology Residency. Subspecialists and fellows in MaternalFetal Medicine staff the Labor and Delivery ward. Epidurals are placed on demand to women with established labor patterns and in active labor. Attending physicians are present at the time of the delivery, which can take place in labor rooms, delivery rooms, or operating rooms as deemed necessary.

In all cases, a clinical diagnosis of shoulder dystocia was made at the time of delivery and a McRobert's maneuver and suprapubic pressure failed to accomplish delivery. Recognizing a more severe form of shoulder dystocia careful documentation of the side of the original head restitution prior to the maneuver (spontaneous external rotation), the direction of the rotary motion exerted on the fetal head and the position of the first delivering shoulder were documented immediately after delivery.

The location of the delivering shoulder was recorded in an approximation to the nearest outlet diameter by intervals of 45 degrees (direct anterior, left or right anterior, left or right transverse, left or right posterior, and direct posterior). Time between delivery of the head and delivery of the shoulders was not recorded.

Neonatal management was customary according to the clinical circumstances and UTMB neonatology protocols.

Maternal and neonatal data extracted was extracted from the respective medical charts. The study was approved by the
Institutional Review Board of the University of Texas Medical Branch at Galveston.

Descriptive statistics were used to summarize the numerical data.

\section{The Carit Maneuver}

The Carit rotational maneuver involves the use of the fetal head and neck as the grasping point to effect a ventral rotation of the fetal trunk, a reduction in the biacromial diameter, and delivery of the shoulders. It can be described as the bimanual rotation of the fetal head while supporting the fetal neck with simultaneous downward traction. The direction of rotation is always opposite to the direction of the spontaneous head restitution.

-Fig. 1 illustrates this obstetric technique and its expected results. In cases where the right shoulder is anterior, the head and neck are grasped bimanually by sliding the middle and annular fingers around the fetal neck (left hand anterior) to rotate the head in a counterclockwise sense with simultaneous downward traction toward the floor ( - Fig. 1; upper panel). Conversely, in cases where the head is facing the left shoulder is anterior, the fetal head and neck are grasped with the right hand anterior and clockwise rotation with downward traction effected ( - Fig. 1; lower panel).

An electronic database search (PubMed and Medline) was performed on the subjects of shoulder dystocia and obstetrical maneuvers, treatment, and/or interventions. Particular emphasis was made on articles reporting on management of shoulder dystocia and obstetrical maneuvers aimed at its relief. The references of these articles were reviewed and pulled if they met the above criteria. Original sources were traced and consulted when possible. No time or language limits were established. A list of the interventions reported for the relief of shoulder dystocia and a tentative classification based on the ultimate mode of delivery was compiled in - Table $1 .^{6-9,13-25}$

\section{Results}

The characteristics of the patients are summarized in - Table 2. Of the eight cases treated, five were of Hispanic ethnicity and only one was a primigravida. Average maternal age and body mass index were $26.7 \pm 5.4$ years and $32.7 \pm 7.5 \mathrm{~kg} / \mathrm{m}^{2}$, respectively.

- Table 3 summarizes shoulder dystocia characteristics as well as maternal morbidity. In most cases (6/8), the spontaneous head restitution (using the fetal occiput as the reference point) occurred in a clockwise direction. In these cases, the right shoulder is presumably impacted under the symphysis pubis (right shoulder dystocia). In two cases, the spontaneous head restitution occurred in a counterclockwise direction (left shoulder impacted under the symphysis or left shoulder dystocia).

In all cases, the direction of rotation of the Carit maneuver was deliberately contralateral (as intended) to the original restitution after McRobert's maneuver and suprapubic pressure failed to deliver the anterior shoulder. If the restitution was to the left (from occiput anterior $[\mathrm{OA}]$ to left occiput 


\section{Carit Maneuver}

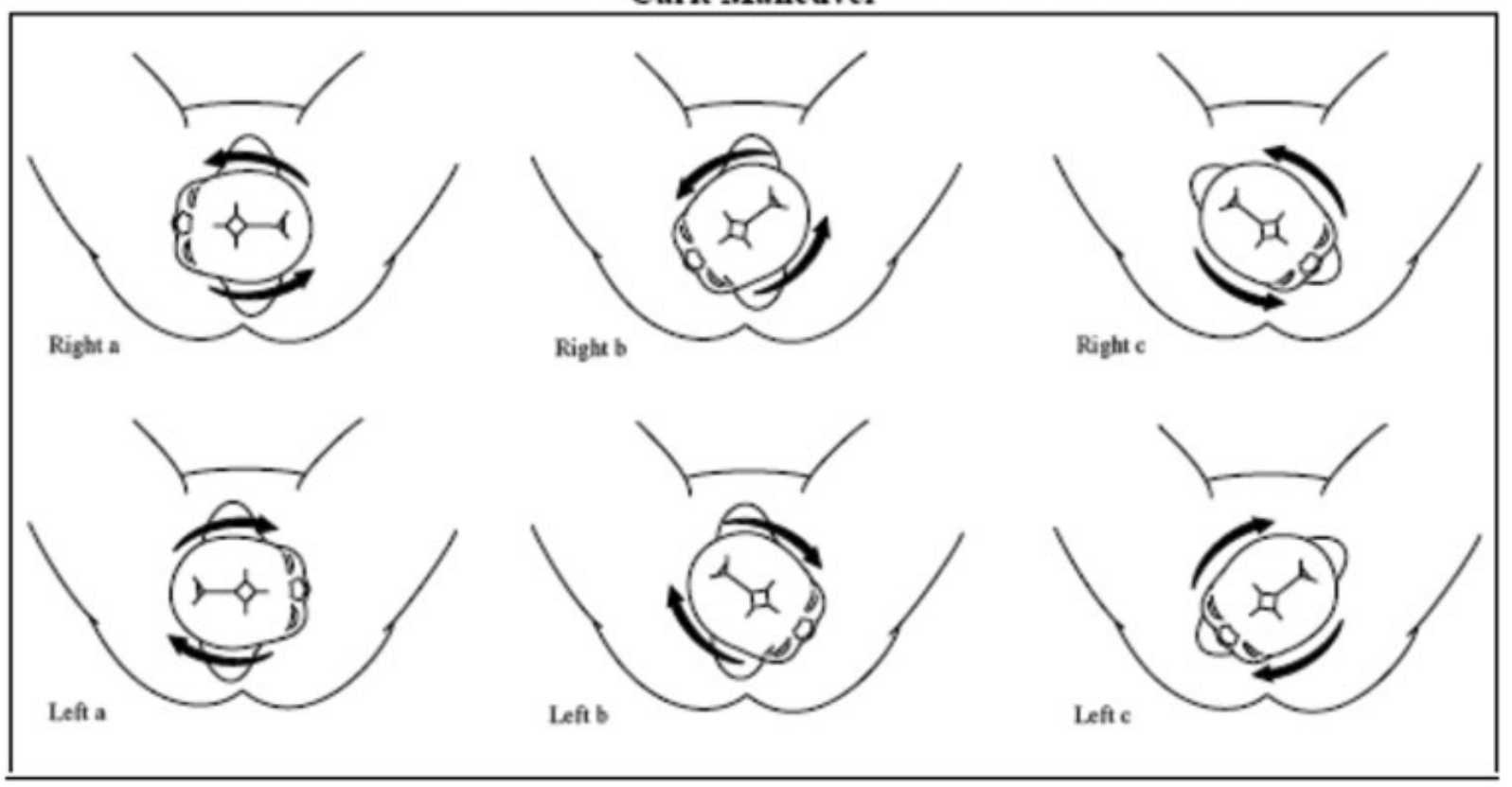

Fig. 1 Illustration of the Carit maneuver: The failure of the right shoulder to deliver is illustrated in the upper panel (left to right). In the lower panel, the opposite situation is depicted. In the Carit maneuver, the fetal head and neck are grasped with both hands between the middle and annular fingers to exert a ventral rotation in the contralateral direction from the original head restitution (direction illustrated by the arrows around the fetal heads).

anterior [LOA] or left occiput transverse [LOT]), the rotation was exerted in a counterclockwise direction. If the spontaneous restitution was to the right (from OA to ROA or ROT), the Carit rotation was exerted in a clockwise direction.

Overall, in half of the cases $(4 / 8)$, the posterior shoulder delivered in a transverse diameter, a quarter $(2 / 8)$ in the anterior oblique diameter, and a quarter $(2 / 8)$ in a direct anterior position. It is noteworthy that in all cases, the delivering shoulder was the originally posterior one as judged by the direction of the documented head restitution preceding the Carit maneuver.

No instances of postpartum hemorrhage were observed. Five of out of the eight patients required some degree of vulvovaginal repair either due to spontaneous lacerations or episiotomies. No advanced degrees of perineal injury (third of fourth degrees) were observed.

Table 1 Interventions described for the relief of shoulder dystocia

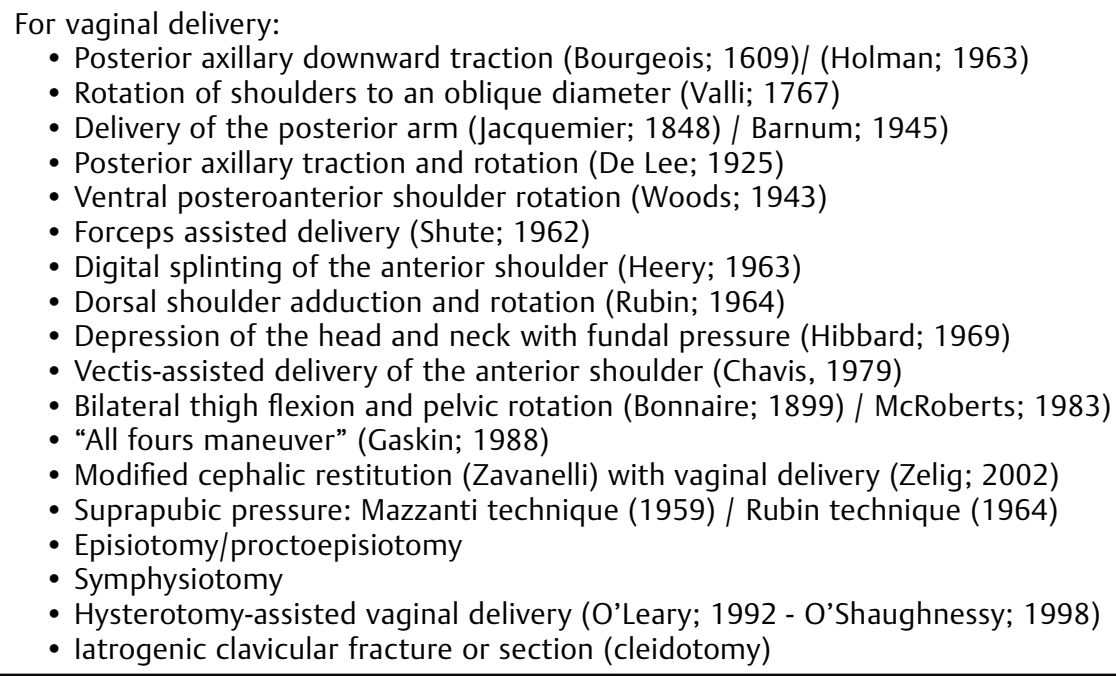

- Rotation of shoulders to an oblique diameter (Valli; 1767)

- Delivery of the posterior arm (Jacquemier; 1848) / Barnum; 1945)

- Posterior axillary traction and rotation (De Lee; 1925)

- Ventral posteroanterior shoulder rotation (Woods; 1943)

- Forceps assisted delivery (Shute; 1962)

- Digital splinting of the anterior shoulder (Heery; 1963)

- Dorsal shoulder adduction and rotation (Rubin; 1964)

- Depression of the head and neck with fundal pressure (Hibbard; 1969)

- Vectis-assisted delivery of the anterior shoulder (Chavis, 1979)

- Bilateral thigh flexion and pelvic rotation (Bonnaire; 1899) / McRoberts; 1983)

- "All fours maneuver" (Gaskin; 1988)

- Modified cephalic restitution (Zavanelli) with vaginal delivery (Zelig; 2002)

- Suprapubic pressure: Mazzanti technique (1959) / Rubin technique (1964)

- Episiotomy/proctoepisiotomy

- Symphysiotomy

- Hysterotomy-assisted vaginal delivery (O’Leary; 1992 - O’Shaughnessy; 1998)

- latrogenic clavicular fracture or section (cleidotomy)

For abdominal delivery:

- Fetal uterine restitution and cesarean delivery (Zavanelli maneuver) (Sandberg; 1985)

Source: Adapted from references. ${ }^{6-11,13-25}$ 
Table 2 Carit maneuver patient characteristics (UTMB 2003-2006)

\begin{tabular}{|l|l|l|l|l|l|l|}
\hline Case & Age & Ethnic background & Gravidity & Parity & Maternal weight $(\mathbf{k g})$ & Maternal BMI $\left(\mathbf{k g} / \mathbf{m}^{2}\right)$ \\
\hline 1 & 22 & Hispanic & 2 & 1 & 57.7 & 24 \\
\hline 2 & 18 & Hispanic & 1 & 0 & 82.9 & 28.1 \\
\hline 3 & 37 & Caucasian & 3 & 2 & 110 & 41.6 \\
\hline 4 & 29 & Asian & 6 & 2 & 75 & 28.3 \\
\hline 5 & 23 & Hispanic & 3 & 2 & 67.7 & 24.4 \\
\hline 6 & 30 & Hispanic & 2 & 1 & 111.3 & 46.3 \\
\hline 7 & 27 & Hispanic & 6 & 4 & 87 & 33.9 \\
\hline 8 & 28 & Caucasian & 2 & 1 & 97.2 & 35.6 \\
\hline
\end{tabular}

Abbreviations: BMI, body mass index; UTMB, University of Texas Medical Branch.

Table 3 Carit maneuver shoulder dystocia characteristics (UTMB 2003-2006)

\begin{tabular}{|l|l|l|l|l|l|c|}
\hline Case & Head position & $\begin{array}{l}\text { Original } \\
\text { restitution }\end{array}$ & $\begin{array}{l}\text { Direction of } \\
\text { rotation }\end{array}$ & $\begin{array}{l}\text { Shoulder } \\
\text { delivered }\end{array}$ & $\begin{array}{l}\text { Location of delivering } \\
\text { shoulder }\end{array}$ & Maternal trauma \\
\hline 1 & LOA & Left & Right & Left & Anterior & 2nd degree perineal laceration \\
\hline 2 & n/a & Left & Right & Left & Transverse diameter & Right labial laceration \\
\hline 3 & n/a & Left & Right & Left & Left transverse & 1st degree perineal laceration \\
\hline 4 & LOA & Left & Right & Left & Left transverse & Right mediolateral episiotomy \\
\hline 5 & n/a & Left & Right & Left & Left oblique & None \\
\hline 6 & n/a & Right & Left & Right & Anterior & $\begin{array}{l}\text { Intact perineum } \\
\text { (small side wall not repaired) }\end{array}$ \\
\hline 7 & LOA & Left & Right & Left & Left oblique & None \\
\hline 8 & n/a & Right & Left & Right & Transverse & 2nd degree perineal laceration \\
\hline
\end{tabular}

Abbreviations: LOA, left occiput anterior; UTMB, University of Texas Medical Branch.

- Table 4 summarizes the neonatal data. The average fetal weight was $4174.2 \pm 670 \mathrm{~g}$ (range: $2,904-5,000 \mathrm{~g}$ ). Five (of 8 ) neonates weighed more than $4,000 \mathrm{~g}$. No cases of neonatal depression were observed in this series. In all but one case, the arterial $\mathrm{pH}$ was above 7.2. The case without arterial blood gases had normal venous cord $\mathrm{pH}$.

\section{Discussion}

Shoulder dystocia is an unpredictable delivery complication that requires prompt and effective interventions for a favorable maternal and fetal resolution. Despite multiple maneuvers described to date (-Table $\mathbf{1}$ ), the management of

Table 4 Neonatal morbidity; Carit maneuver. UTMB; 2003-2006

\begin{tabular}{|l|l|l|l|l|}
\hline Case: & Neonatal weight & Apgar scores $(1 / 5 \mathrm{~min})$ & Arterial $\mathrm{pH} / \mathrm{pCO}_{2} / \mathrm{HCO}_{3}$ & Neonatal morbidity \\
\hline 1 & $3,520 \mathrm{~g}$ & $8 / 9$ & $7.21 / 59 \mathrm{~mm} \mathrm{Hg} / 21 \mathrm{mmol} / \mathrm{L}$ & None \\
\hline 2 & $3,870 \mathrm{~g}$ & $8 / 9$ & $7.28 / 51 \mathrm{~mm} \mathrm{Hg} / \mathrm{N} / \mathrm{A}$ & None \\
\hline 3 & $4,960 \mathrm{~g}$ & $6 / 8$ & $7.24 / 65 \mathrm{~mm} \mathrm{Hg} / 27 \mathrm{mmol} / \mathrm{L}$ & None \\
\hline 4 & $4,400 \mathrm{~g}$ & $8 / 9$ & $7.22 / 48 \mathrm{~mm} \mathrm{Hg} / 19 \mathrm{mmol} / \mathrm{L}$ & None \\
\hline 5 & $2,904 \mathrm{~g}$ & $8 / 9$ & $7.2 / 71 \mathrm{~mm} \mathrm{Hg} / 16 \mathrm{mmol} / \mathrm{L}$ & None \\
\hline 6 & $4,230 \mathrm{~g}$ & $8 / 9$ & $7.21 / 65 \mathrm{~mm} \mathrm{Hg} / 18 \mathrm{mmol} / \mathrm{L}$ & None \\
\hline 7 & $5,000 \mathrm{~g}$ & $8 / 8$ & $7.29 / 64 \mathrm{~mm} \mathrm{Hg} / 19 \mathrm{mmol} / \mathrm{L}$ & None \\
\hline 8 & $4,510 \mathrm{~g}$ & $8 / 9$ & $\begin{array}{l}\left.{ }^{*}\right) \\
\text { V: } 7.34 / 46 \mathrm{~mm} \mathrm{Hg} / 33 \mathrm{mmol} / \mathrm{L}\end{array}$ & None \\
\hline
\end{tabular}

$\left.{ }^{*}\right)$ : Arterial cord gases not obtained. 
shoulder dystocia is empirical and current guidelines of management are arbitrary. ${ }^{2}$ Current guidelines recommend four basic maneuvers including McRobert's maneuver, suprapubic pressure, delivery of posterior arm, and internal rotation. $^{26,27}$ After failure of the McRobert's maneuver, proposed management strategies follow the individual authors' preference of the most complicated, difficult, and infrequently performed maneuvers. ${ }^{6-9}$ Recently the delivery of the posterior shoulder has recently gained popularity as secondary step after its association with high overall success rates. ${ }^{28,29}$ Unfortunately, it can be associated with a substantial increase in the incidence of neonatal humeral fractures. $^{30}$

Suboptimal resolution of shoulder dystocia should be addressed by proper response protocol, education, and training. Studies have shown significant improvement after optimizing clinical response strategies. ${ }^{31-33}$ In this regard, the knowledge of different maneuvers by obstetricians and other birth attendants would be of the greatest value in their daily practice as different cases would likely benefit from different interventions. ${ }^{7,8}$

Fetal maneuvers for the relief of shoulder dystocia are believed to have additional biomechanical advantages over maternal maneuvers in that they achieve the physiologic rotation required for the shoulders to descend from the inlet and progress unobstructed forward through the midpelvis and eventually the outlet. ${ }^{12}$

The observed mechanism of action of the Carit maneuver contrasts sharply with our assumption and previously held belief that the ventral rotation of the fetal head and neck displaced the anterior shoulder off the symphysis pubis to an oblique diameter, where it was delivered.

We speculate that the ventral rotation of the Carit maneuver reduces the biacromial diameter and trunk circumference in an analogous manner to the Rubin maneuver, allowing for the rotation of the fetal trunk and ultimately the delivery of the originally posterior shoulder, onto an anterior diameter. These characteristics make the Carit manipulation a unique and distinct rotational maneuver.

Although the digital anteroposterior displacement (Woods' maneuver) or the posteroanterior displacement (Rubin's maneuver) are sound options, from a practical standpoint, we have found that these interventions have two shortcomings. ${ }^{13,17}$ First, as experienced by other practitioners there is little room in the birthing canal to introduce one's hand and accomplish these rotations. ${ }^{17,20,34}$ Second, in the attempt to rotate the anterior shoulder, one has to free the grip from the fetal head, resulting in the loss of axial traction on the presentation. In this situation, the mere rotation of the shoulders can inadvertently result in a loss of fetal station. This principle was acknowledged by both Woods and Rubin in their respective articles. Dr. Woods assisted the intrapelvic rotation of the fetus by preserving fetal station through "a downward thrust on the buttocks of the baby."13 Two decades later Rubin recommended fundal pressure by an assistant "after the shoulders are disimpacted." 17

More recently, fundal pressure has been identified as a contributor to greater fetal morbidity. ${ }^{2,35}$ Instead of attempt- ing a direct rotation of the shoulders, the intervention described here utilizes the fetal head and neck as the grasping point to accomplish the rotation of the trunk and shoulders.

One of the advantages of the Carit maneuver as a bimanual intervention, it can be easily performed by left- or righthanded individuals, regardless of fetal trunk position. Its use may be particularly beneficial in places where nonskilled obstetrical attendants are responsible for deliveries, since its implementation requires minimal training as demonstrated by the two cases performed by residents under direct faculty guidance with no previous theoretical or practical knowledge of the maneuver.

Given the simplicity and nonmanipulative character of the McRobert's maneuver with suprapubic pressure, we propose the use of the Carit maneuver as a second intervention or maneuver in the management of shoulder dystocia. We believe that its use might prevent maternal and fetal injuries.

While we have not experienced any noticeable fetal trauma associated to the use of the Carit maneuver, we acknowledge that one of the limitations of this report is its small number, which is merely attempting to report the maneuver and its mechanism of action.

To prevent potential fetal trauma with the Carit manipulation, we caution our colleagues on a gentle and steady rotation of the head after 90 degrees, rather than a jerky movement or extreme rotation (more than 180 degrees from the original head position). Usually no more than 90 to 135 degree rotation of the head (normal range up to 220 degree) is required to accomplish the posterior shoulder displacement and delivery. ${ }^{35}$

To our knowledge, this is the first cohort of shoulder dystocia cases where the spontaneous head spontaneous restitution, side of shoulder dystocia and the observation of which shoulder delivers first and where, were prospectively noted and documented. We recommend that future evaluations of the effectiveness of obstetrical maneuvers aimed at the relief of shoulder dystocia consider some of the descriptors used in this report. This information should afford us a better understanding of the mechanism of action of this obstetrical complication and eventually lead us to a better and individualized management.

We propose to our colleagues that the Carit maneuver described here is a novel, quick, and successful intervention in the management of shoulder dystocia. Further utilization of this fetal rotation will reveal its true profile of efficacy and safety when compared with other, more widely utilized obstetrical maneuvers.

\section{Conflict of Interest}

None.

\section{Acknowledgments}

We acknowledge the contributions of Patrick Rozenberg, MD and Anthony R Gregg, MD for their critical review of the manuscript. 


\section{References}

1 Langer O, Berkus MD, Huff RW, Samueloff A. Shoulder dystocia: should the fetus weighing greater than or equal to 4000 grams be delivered by cesarean section? Am J Obstet Gynecol 1991;165(4 Pt 1):831-837

2 Gherman RB, Chauhan S, Ouzounian JG, Lerner H, Gonik B, Goodwin TM. Shoulder dystocia: the unpreventable obstetric emergency with empiric management guidelines. Am J Obstet Gynecol 2006;195(03):657-672

3 Committee on Practice Bulletins-Obstetrics. Practice bulletin no 178: shoulder dystocia. Obstet Gynecol 2017;129(05):e123-e133https://journals.lww.com/greenjournal/Abstract/ 2017/05000/Practice_Bulletin_No_178_Shoulder_Dystocia.47. aspx Accessed January 032019

4 Chauhan SP, Gherman R, Hendrix NW, Bingham JM, Hayes E. Shoulder dystocia: comparison of the ACOG practice bulletin with another national guideline. Am J Perinatol 2010;27(02):129-136

5 Hope P, Breslin S, Lamont L, et al. Fatal shoulder dystocia: a review of 56 cases reported to the Confidential Enquiry into Stillbirths and Deaths in Infancy. Br J Obstet Gynaecol 1998;105(12):1256-1261

6 Resnik R. Management of shoulder girdle dystocia. Clin Obstet Gynecol 1980;23(02):559-564

7 Naef RW III, Martin JN Jr. Emergent management of shoulder dystocia. Obstet Gynecol Clin North Am 1995;22(02):247-259

8 Bennett BB. Shoulder dystocia: an obstetric emergency. Obstet Gynecol Clin North Am 1999;26(03):445-458, viii

9 Gherman RB. Shoulder dystocia: prevention and management. Obstet Gynecol Clin North Am 2005;32(02):297-305, x

10 McFarland MB, Langer O, Piper JM, Berkus MD. Perinatal outcome and the type and number of maneuvers in shoulder dystocia. Int J Gynaecol Obstet 1996;55(03):219-224

11 Gherman RB, Goodwin TM, Souter I, Neumann K, Ouzounian JG, Paul RH. The McRoberts' maneuver for the alleviation of shoulder dystocia: how successful is it? Am J Obstet Gynecol 1997;176(03): 656-661

12 Allen RH. On the mechanical aspects of shoulder dystocia and birth injury. Clin Obstet Gynecol 2007;50(03):607-623

13 Woods CE. A principle of physics as applicable to shoulder dystocia. Obstet Gynecol 1943;45(05):796-804

14 Mazzanti GA. Delivery of the anterior shoulder; a neglected art. Obstet Gynecol 1959;13(05):603-607

15 Shute WB. Management of shoulder dystocia with the Shute parallel forceps. Am J Obstet Gynecol 1962;84:936-939

16 Heery RD. A method to relieve shoulder dystocia in vertex presentation. Obstet Gynecol 1963;22:360-361

17 Rubin A. Management of shoulder dystocia. JAMA 1964; 189:835-837

18 Hibbard LT. Shoulder dystocia. Obstet Gynecol 1969;34(03): 424-429

19 Chavis WM. A new instrument for the management of shoulder dystocia. Int J Gynaecol Obstet 1978-1979-197916(04):331-332
20 Sandberg EC. The Zavanelli maneuver: a potentially revolutionary method for the resolution of shoulder dystocia. Am J Obstet Gynecol 1985;152(04):479-484

21 Meenan AL, Gaskin IM, Hunt P, Ball CA. A new (old) maneuver for the management of shoulder dystocia. J Fam Pract 1991;32(06): 625-629

22 Goodwin TM, Banks E, Millar LK, Phelan JP. Catastrophic shoulder dystocia and emergency symphysiotomy. Am J Obstet Gynecol 1997;177(02):463-464

23 O'Leary JA, Cuva A. Abdominal rescue after failed cephalic replacement. Obstet Gynecol 1992;80(3 Pt 2):514-516

24 O'Shaughnessy MJ. Hysterotomy facilitation of the vaginal delivery of the posterior arm in a case of severe shoulder dystocia. Obstet Gynecol 1998;92(4 Pt 2):693-695

25 Beer E. History of extraction of the posterior arm to resolve shoulder dystocia. Obstet Gynecol Surv 2006;61(03):149-151

26 ACOG Committee on Practice Bulletins-Gynecology, The American College of Obstetrician and Gynecologists. ACOG practice bulletin clinical management guidelines for obstetrician-gynecologists. Number 40, November 2002. Obstet Gynecol 2002;100 (5 Pt 1):1045-1050

27 Royal College Obstetricians and Gynecologists. Shoulder dystocia. Green-Top Guideline No. 42. RCOG 2012. Available at: https:// www.rcog.org.uk/globalassets/documents/guidelines/gtg_42. pdf. Accessed January 03, 2019.

28 Hoffman MK, Bailit JL, Branch DW, et al; Consortium on Safe Labor. A comparison of obstetric maneuvers for the acute management of shoulder dystocia. Obstet Gynecol 2011;117(06): 1272-1278

29 Poggi SH, Spong CY, Allen RH. Prioritizing posterior arm delivery during severe shoulder dystocia. Obstet Gynecol 2003;101(5 Pt 2):1068-1072

30 Gold S, Hirsch D, Schutzman D, Cohen A, Jaspan D, Goldberg J. Delivery of the posterior arm as initial maneuver to relieve shoulder dystocia increased neonatal humeral fractures. . [24D] Obstet Gynecol 2018;131(05):47s

31 Cusick W, Cox RL, Santos P, Hefele JG, Darden J. Shoulder dystocia response: improving neonatal outcomes. . [658]Am J Obstet Gynecol 2017;216(01):386s

32 Sienas LE, Hedriana HL, Wiesner S, Pelletreau B, Wilson MD Shields LE. Decreased rates of shoulder dystocia and brachial plexus injury via an evidence-based practice bundle. Int J Gynaecol Obstet 2017;136(02):162-167

33 Gurewitsch Allen ED, Brown Will SE, Allen RH, Satin AJ. Targeted training effort improves shoulder dystocia management and outcomes. Am J Obstet Gynecol 2017;216(01):517s

34 Morris WIC. Shoulder dystocia. J Obstet Gynaecol Br Emp 1955; 62:302-306

35 Gross SJ, Shime J, Farine D. Shoulder dystocia: predictors and outcome. A five-year review. Am J Obstet Gynecol 1987;156(02): 334-336 